\title{
Phylogenetic analysis of Australian species of Veronica (V. section Labiatoides; Plantaginaceae)
}

\author{
Dirk C. Albach ${ }^{\mathrm{A}, \mathrm{C}}$ and Barbara G. Briggs ${ }^{\mathrm{B}}$ \\ A Institut für Biologie und Umweltwissenschaften, Carl von Ossietzky-Universität Oldenburg, \\ Carl von Ossietzky-Strasse 9-11, D-26111 Oldenburg, Germany. \\ ${ }^{B}$ National Herbarium of New South Wales, Royal Botanic Garden, Mrs Macquaries Road, \\ Sydney, NSW 2000, Australia. \\ ${ }^{\mathrm{C}}$ Corresponding author. Email: dirk.albach@uni-oldenburg.de
}

\begin{abstract}
Phylogenetic analyses of DNA-sequence data have revealed that the southern hemisphere species of Veronica are derived from within the northern hemisphere Veronica clade. Previous analyses focussed on the species in New Zealand and included at maximum 7 of 23 species of section Labiatoides from Australia. In the present study, we used nuclear ribosomal-ITS and plastid $n d h \mathrm{~F}-r p l 32$-spacer sequence data of all species currently recognised in Australia to analyse phylogenetic patterns. Most importantly, herbaceous species from coastal calcareous sands or limestone habitats do not form a clade with those from shady, moist forest habitats, as formerly believed, but seem to be independently derived from woody species. Incongruence between results from nuclear- and plastid-DNA markers suggest hybridisation to be an important factor in the evolution of the group. Our sample of $V$. parnkalliana included alleles similar to $V$. decorosa and $V$. novae-hollandiae at both loci, which suggests a hybrid origin.
\end{abstract}

Received 4 May 2012, accepted 12 July 2012, published online 10 October 2012

\section{Introduction}

Veronica, the largest genus of Plantaginaceae in its new circumscription (Angiosperm-Phylogeny-Group 2003; Albach et al. 2005a) is most species rich in Europe, south-western Asia and New Zealand ( $V$. section Hebe). Therefore, recent phylogenetic analyses in the genus have focussed on species from these three areas (e.g. Wagstaff and Garnock-Jones 1998; Albach and Chase 2001; Wagstaff et al. 2002; Albach et al. $2004 a$ ). These analyses have demonstrated the inadequacy of previous classifications to delimit coherent evolutionary units. Consequently, the evolution of various characters had to be reinterpreted (e.g. Albach et al. 2004a, 2004b, 2005b, 2008) and the intrageneric classification of the genus was revised (Albach et al. 2004c; Garnock-Jones et al. 2007; Albach 2008). Most notably, the large genus Hebe and its segregate genera, such as Parahebe W.R.B.Oliv., Chionohebe B.G.Briggs \& Ehrend. and Derwentia Raf., were (re-)classified under the genus Veronica. Despite these efforts, the $\sim 23$ native Australian species of the genus, some of which have also been referred in the past to the genera Parahebe (Briggs and Ehrendorfer 1968; Heads 1994) and Derwentia (Briggs and Ehrendorfer 1992), have mostly been neglected in these analyses. Most previous DNA-based phylogenetic analyses exclusively relied on nuclear ribosomal ITS sequences. For example, Wagstaff and Garnock-Jones (1998) included four Australian species and demonstrated a well supported sister-group relationship of three of these species with the
New Zealand species, whereas Veronica (Chionohebe) densifolia was embedded among New Zealand species. Wagstaff et al. (2002) increased the sampling to nine Australian species, seven of which (i.e. all except $V$. densifolia and $V$. ciliolata) were again moderately supported as a clade that is sister to the New Zealand Hebe complex; however, resolution of relationships within the group was limited. In contrast, their analysis of three plastid-rbcL sequences revealed the Australian species as a polyphyletic assemblage. A similar result was retrieved by Albach et al. (2005c) using plastid trnL-intron and trnL-trnF-spacer sequences (subsequently $\operatorname{trn} \mathrm{L}-\mathrm{F}$ ), although the resolution was low because of the low sequence variability. Furthermore, the combined analysis of ITS and trnL-F sequences by Albach et al. (2005c) gave strong support for the monophyly of the Australian clade and even stronger support than in the analysis of ITS alone. A similar pattern was retrieved by Albach and Meudt (2010).

Given the great progress in understanding phylogenetic relationships by molecular systematic analyses and especially the controversy around generic delimitation in Veronica sensu lato (Brummitt 2006; Garnock-Jones et al. 2007; Albach 2008), it is important to investigate the phylogenetic relationships among the Australian species of Veronica in more detail. These species exemplify well the problems of differentiating Veronica from Hebe and Parahebe, especially because they include herbaceous species within the broad and mostly 
woody Hebe clade (Fig. 1). Understanding character evolution in the group may therefore help understand the differentiation of Hebe within Veronica. Bentham $(1846,1869)$ classified the 13 Australian species known at that time almost equally in the following two sections: section Hebe, including also the species from New Zealand, and section Chamaedrys, including also many species from Eurasia. Section Hebe was distinguished from section Chamaedrys by being (1) 'evergreen shrubs or densely tufted or tall and erect perennial herbs' in contrast to 'herbs, from a perennial usually creeping rootstock, diffuse ascending or erect' and (2) 'capsule more or less turgid and septicidally dividing when ripe' not 'capsule compressed, opening loculicidally on the margin' (Bentham 1869). This distinction was kept up by following authors, although Wettstein (1891) elevated the Australian members of section Hebe to a separate section, namely, section Labiatoides. This group was recognised at generic rank under the name Derwentia Raf. by Briggs and Ehrendorfer (1992). Garnock-Jones (1993), in a cladistic analysis of morphological characters, found this genus to be intermediate between Veronica and Hebe sensu lato, although he could not give an unambiguous synapomorphy for the genus. Other Australian species here recognised within the Australian Veronica section Labiatoides ( $V$. formosa, $V$. lithophila) clade are nested within Hebe in the cladistic analysis of Garnock-Jones (1993). Finally, Heads (1994) did not recognise Derwentia at generic rank, but considered the species of Derwentia to belong to Parahebe, along with species distributed also in New Zealand and New Guinea.

We here provide a phylogenetic analysis of nuclear ITS sequences and plastid $n d h \mathrm{~F}-r p l 32$-spacer sequences to test these taxonomic concepts. We consider the main clade of native Australian species to belong to Veronica section Labiatoides (Garnock-Jones et al. 2007) equating to the Australian clade identified by Wagstaff et al. (2002), and are here seeking to identify intra-sectional groupings. Furthermore, we use these phylogenetic hypotheses to search for patterns of hybridisation and infer trends in habitat, chromosomal, habit and fruit morphological evolution.

\section{Material and methods}

\section{Plant materials}

There are 23 species of Veronica native to Australia recognised in $V$. section Labiatoides (Garnock-Jones et al. 2007). On the basis of previous analyses, the section is most likely monophyletic (see above). We have sampled all 23 species and three of the five subspecies recognised in $V$. derwentiana (Table 1). As outgroups, we have chosen four accessions of three species from the same subgenus, $V$. subgenus Pseudoveronica J.B.Armstr., from New Guinea and New Zealand, for which sequences were already available from previous studies. Including more divergent outgroups has been difficult in the $n d h \mathrm{~F}-r p l 32$ dataset because of alignment ambiguities and they have, therefore, been left out in both datasets.

\section{DNA isolation and sequencing}

DNA was isolated from $\sim 20 \mathrm{mg}$ of tissue from silica gel-dried leaves by using the DNeasy plant minikit (Qiagen $\mathrm{GmbH}$, Hilden, Germany), following the manufacturer's instructions. The quality of the extracted DNA was checked on $0.8 \%$ TBE-agarose gels and the concentration was measured spectrophotometrically with a GeneQuant RNA/DNA calculator (Pharmacia, Cambridge, UK).

For the phylogenetic analyses, we used two DNA regions demonstrated to have suitable variation in Veronica, namely the nuclear ribosomal internal-spacer region (ITS) and the plastidDNA $n d h \mathrm{~F}-r p l 32$ intergenic-spacer region (subsequently $n d h \mathrm{~F}-r p l 32)$. Whereas the former has been used extensively across the genus (Wagstaff and Garnock-Jones 1998; Albach and Chase 2001; Albach and Meudt 2010), ndhF-rpl32 has not been used in analyses of Veronica before; however, it has been demonstrated to have high variation in the study group in preliminary investigations. For amplification and sequencing of ITS, we used primers ITS A (Blattner 1999) and ITS 4 (White et al. 1990), whereas for $n d h \mathrm{~F}-r p l 32$ we used primers ndhF and $\mathrm{rpl32F}$ (both Shaw et al. 2007). PCR reactions

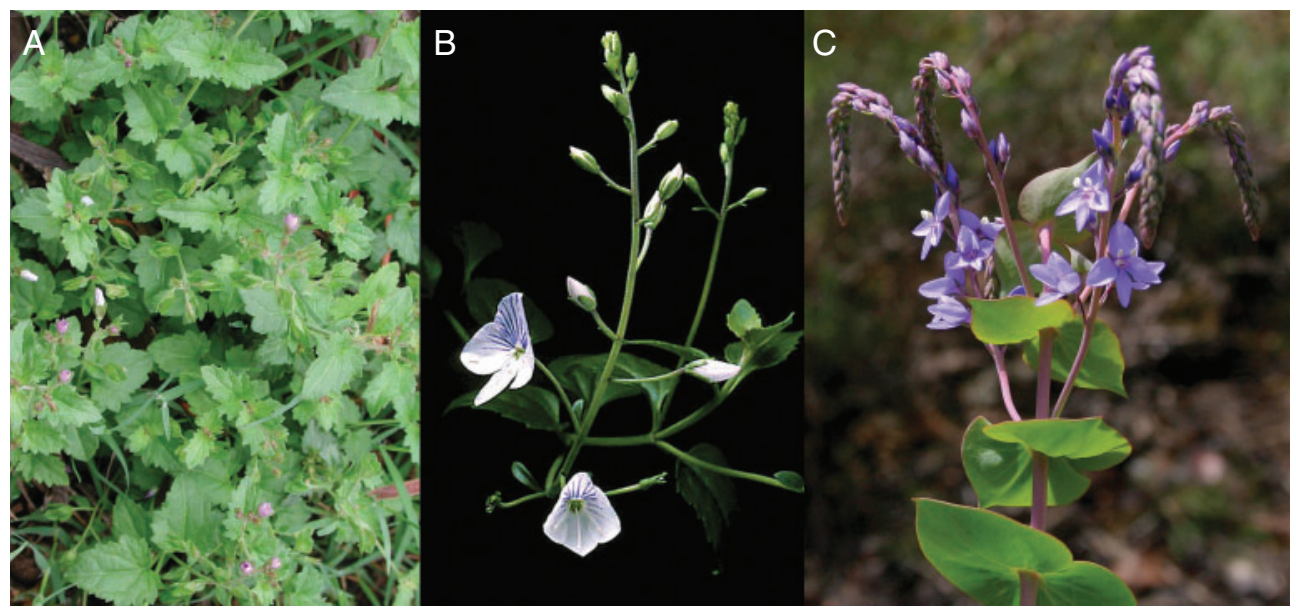

Fig. 1. A. Veronica plebeia; B. V. lithophila; C. V. perfoliata. A and B are herbaceous and stoloniferous; C has soft-woody stems that are mostly replaced annually. Photos: L. von Richter (A), J. Plaza (B) and A. N. Rodd (C). 


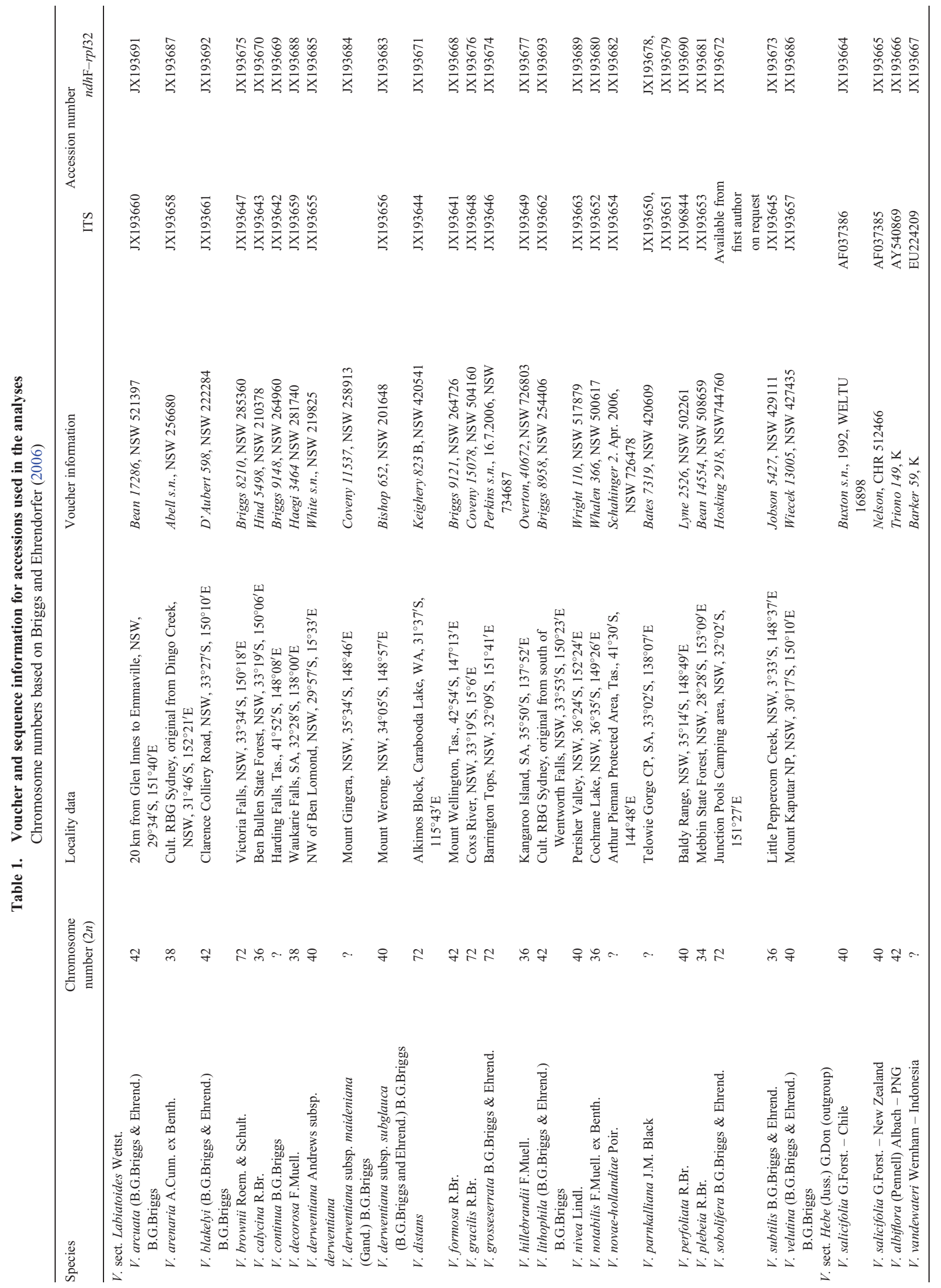


$(25 \mu \mathrm{L})$ included $2-2.5 \mathrm{mM} \mathrm{MgCl}_{2}, 8 \mathrm{mM}$ bovine serum

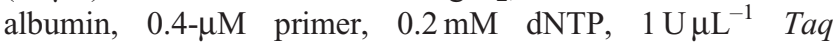
polymerase (New England Biolabs, Ipswich, MA, USA), $1 \times$ polymerase buffer and $1 \mu \mathrm{L}$ of DNA. ITS sequences were amplified using the following program: $2 \mathrm{~min}$ at $95^{\circ} \mathrm{C} ; 36$ cycles of $1 \mathrm{~min}$ at $95^{\circ} \mathrm{C}, 1 \mathrm{~min}$ at $50-55^{\circ} \mathrm{C}$, and $1.5-2 \mathrm{~min}$ at $72^{\circ} \mathrm{C}$; and $5 \mathrm{~min}$ at $72^{\circ} \mathrm{C}$.

PCR products were cleaned using QIAquick PCR purification kit (Qiagen GmbH, Hilden, Germany), following the manufacturer's protocols. PCR fragments of cpDNA of the highly polymorphic $V$. parnkalliana and the ITS sequence of $V$. derwentiana subsp. maideniana were cloned into the pGEM T-easy vector (Promega $\mathrm{GmbH}$, Mannheim, Germany) and processed following the manufacturer's instructions. Three plasmids were picked and sequenced.

Sequencing reactions $(10 \mu \mathrm{L})$ were carried out using $1 \mu \mathrm{L}$ of the Taq DyeDeoxy Terminator Cycle Sequencing mix (Applied Biosystems Inc., Foster City, CA, USA) and the same primers as for PCR, and run out on automated sequencers. Both strands were sequenced. Sequences were assembled and edited using Sequencher 4.7.2 (Gene Codes Corporation, Ann Arbor, MI, USA). Heterogeneous sites were coded as polymorphic. Assembled sequences were manually aligned before analysis (available from the first author on request).

\section{Data analysis - DNA sequences}

DNA sequences were analysed in parsimony, likelihood and Bayesian frameworks. Parsimony analyses were conducted in PAUP v.4a120 (Swofford 2002), with random starting tree, random taxon addition (10 replicates), tree bisection reconnection (TBR) branch swapping and 'MulTrees' in effect. To test the influence of indels, analyses were run with either gaps treated as missing data or gap positions coded according to the modified complex indel coding, as defined by Simmons et al. (2007), using SeqState v.1.4.1 (Müller 2005). Parsimony analyses were repeated three times, finding the same most parsimonious trees. We analysed 1000 bootstrap replicates with the same settings; however, the maximum number of trees kept for each replicate was restricted to 50. Likelihood analyses were likewise analysed in PAUP v.4a120 (Swofford 2002), after evaluating different models in jModeltest (Posada 2008), and choosing a model based on the Akaike's information criterion, which found the F81 $+\Gamma$-model to be the best for the $n d h \mathrm{~F}-r p l 32$ dataset and the TPM 3 uf $+\Gamma$ - model for the ITS dataset. A likelihood analysis of the $n d h \mathrm{~F}-r p l 32$ dataset constrained so that $V$. formosa and $V$. continua were sister taxa was conducted and the optimal constrained trees were compared using the Shimodaira-Hasegawa tests ( $\mathrm{SH})$ as implemented in PAUP4.0b10 (Swofford 2002), with the model estimated as above, using RELL optimisation and 10000 bootstrap (BS) replicates. Bayesian analyses were conducted using MrBayes v.3.1.2 (Ronquist and Huelsenbeck 2003), after evaluating the best model in MrModeltest v.2.3 (see http://www.abc.se/ $\sim$ nylander/mrmodeltest $2 /$ mrmodeltest 2 .htm, accessed 27 July 2012), which was the GTR $+\Gamma+\mathrm{I}$ in both cases. Analyses were run for three million generations, sampling every 100th generation and discarding the first $25 \%$ as burnin. Stationarity was checked in Tracer v. 1.5 (see http://tree.bio.ed.ac.uk/ software/tracer/, accessed 27 July 2012). Because including gap characters in parsimony analyses had no influence on the resulting topology, gap characters were ignored in likelihood and Bayesian analyses. To affirm monophyly of $V$. section Labiatoides, the new ITS sequences generated for the present study were combined with the dataset of Albach and Meudt (2010), which sampled all subgenera and major clades of Veronica, and analysed using MrBayes v. 3.1 (Ronquist and Huelsenbeck 2003), as described by Albach and Meudt (2010).

\section{Results}

The $n d h \mathrm{~F}-r p l 32$ dataset included 30 accessions and 785 aligned nucleotide sites, plus 13 gap characters. Of these, 106 were variable and 43 were parsimony-informative (including seven gap characters). Plasmid sequences of $V$. parnkalliana revealed two different haplotypes among the three sequences (termed Clones 1 and 2). The analysis with gaps treated as missing data resulted in 875 most parsimonious trees (111 steps, consistency index (CI; excluding uninformative characters) 0.82 , retention index (RI) 0.91), whereas the analysis with gaps coded under modified complex indel coding was stopped when 5000 most parsimonious trees (147 steps, CI 0.75, RI 0.83) were reached. The optimal topology retrieved by the latter analysis was congruent with that of the former analysis. The likelihood analysis (GC content $26 \%$, gamma parameter 0.596 ) found five optimal trees that are a subset of the most parsimonious trees without gap characters (Fig. 2). All nodes supported by more than $70 \%$ posterior probability in the Bayesian analysis were also found in the likelihood analysis (Fig. 2).

All analyses of $n d h \mathrm{~F}-r p l 32$ data found four main clades, one consisting of $V$. parnkalliana (Clone 1 ) and $V$. decorosa, the second of $V$. blakelyi, $V$. arcuata, $V$. perfoliata and $V$. derwentiana subsp. maideniana, the third of $V$. distans, $V$. hillebrandii, $V$. parnkalliana (Clone 2) and $V$. novaehollandiae, and the fourth consisting of all other species. A topology with $V$. formosa and $V$. continua forming sister species, as suggested by morphological features, was rejected by the Shimodaira-Hasegawa test $(P<0.02)$.

The ITS analyses included 750 aligned characters, with 569 of them constant and 145 parsimony-informative, plus 13 gap characters, four of them parsimony-informative. Plasmid sequences of $V$. parnkalliana revealed two different haplotypes among the three sequences (termed Clones 1 and 2). Direct sequencing of the ITS region of $V$. derwentiana subsp. maideniana gave highly heterogeneous sequences and plasmid sequencing remained unsuccessful despite several attempts. Only a small piece of sequence could be retrieved for $V$. sobolifera. Analyses were repeated without the sequence and did not differ from those including the sequence. Therefore, we show the topology including the sequence and support values without it. The analysis with gaps treated as missing data resulted in 18 most parsimonious trees (419 steps, CI 0.57, RI 0.70). The analyses with gaps coded under the modified complex indel coding found the same 18 trees as optimal result (434 steps). The likelihood analysis retrieved an optimal phylogeny with the same topology as one of the most parsimonious trees (Fig. 3). Support for internal clades in 


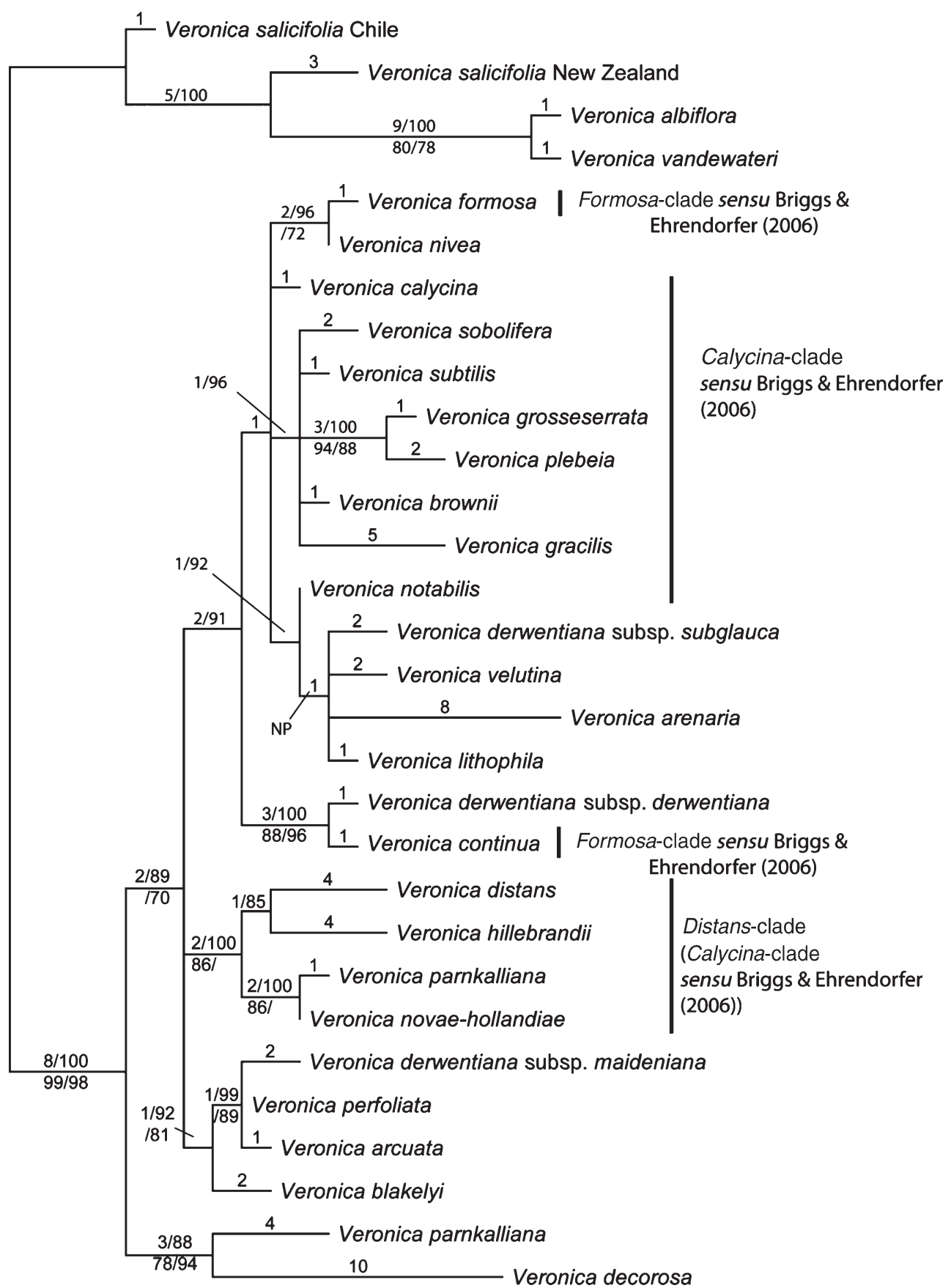

Fig. 2. One of five phylograms resulting from likelihood analysis of $n d h \mathrm{~F}-r p l 32$. Branch not present in all optimal trees is marked with NP. Numbers above the branches indicate steps under parsimony criterion, followed by posterior probabilities from Bayesian analysis. Numbers below branches indicate parsimony bootstrap support for analysis with gaps scored as missing data, followed by those for the analysis with gaps coded under the modified complex indel coding model. Only values $>70$ are reported.

Veronica section Labiatoides is much weaker in ITS than in the plastid-DNA dataset, making it difficult to designate certain clades. The ITS analysis found the same clade consisting of $V$. distans, V. hillebrandii, V. parnkalliana (Clone 1) and $V$. novae-hollandiae as in the $n d h \mathrm{~F}-r p l 32$ analyses, but otherwise supported only clades of three or two sequences.
The monophyly of $V$. section Labiatoides was confirmed by analysing the new ITS sequences with the dataset of Albach and Meudt (2010). The addition of the new sequences did not lead to any topological change outside $V$. subgenus Pseudoveronica, with the exception of $V$. crista-galli moving into a position as sister to $V$. subgenus Pellidosperma rather 


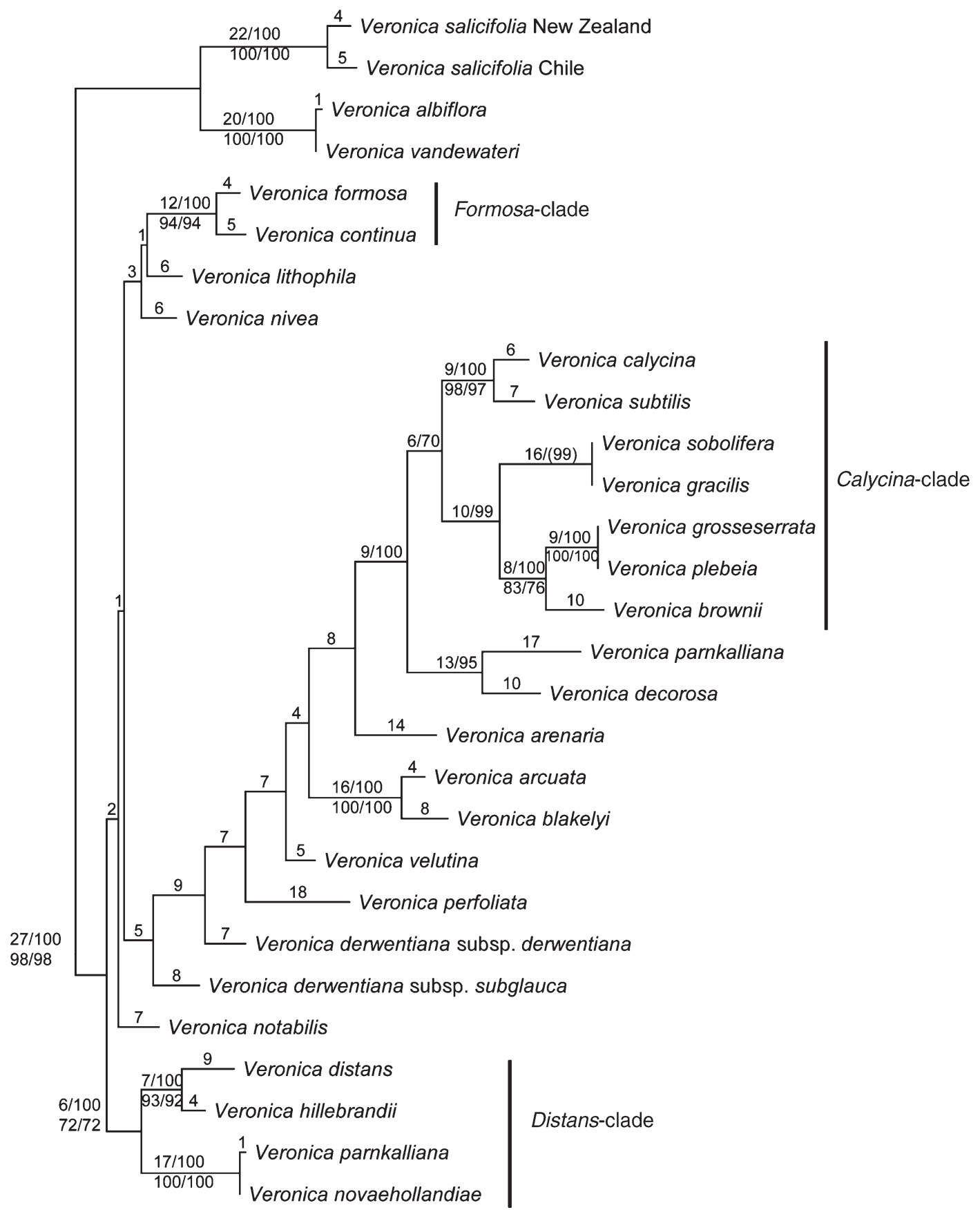

Fig. 3. Optimal phylogram resulting from likelihood analysis of ITS. Numbers above the branches indicate steps under parsimony criterion, followed by posterior probabilities from Bayesian analysis. Numbers below branches indicate parsimony bootstrap support for analysis with gaps scored as missing data, followed by those for the analysis with gaps coded under the modified complex indel coding model. Only values $>70$ are reported. Note that support values were estimated, with Veronica sobolifera excluded because of short sequence length.

than sister to the 'verrucate clade' and $V$. chamaepithyoides as sister to $V$. section Labiatoides rather than sister to $V$. subgenus Pseudoveronica (Fig. 4). Posterior probabilities varied between the analyses by $\pm 10 \%$. The two analyses of ITS differed also in the rooting of $V$. section Labiatoides and showed some minor topological differences at internal nodes.

\section{Discussion}

Intrasectional relationships

The monophyly of the Australian Veronica section Labiatoides has been demonstrated in previous analyses that sampled broadly across the genus, but sampled just a small subset of species 


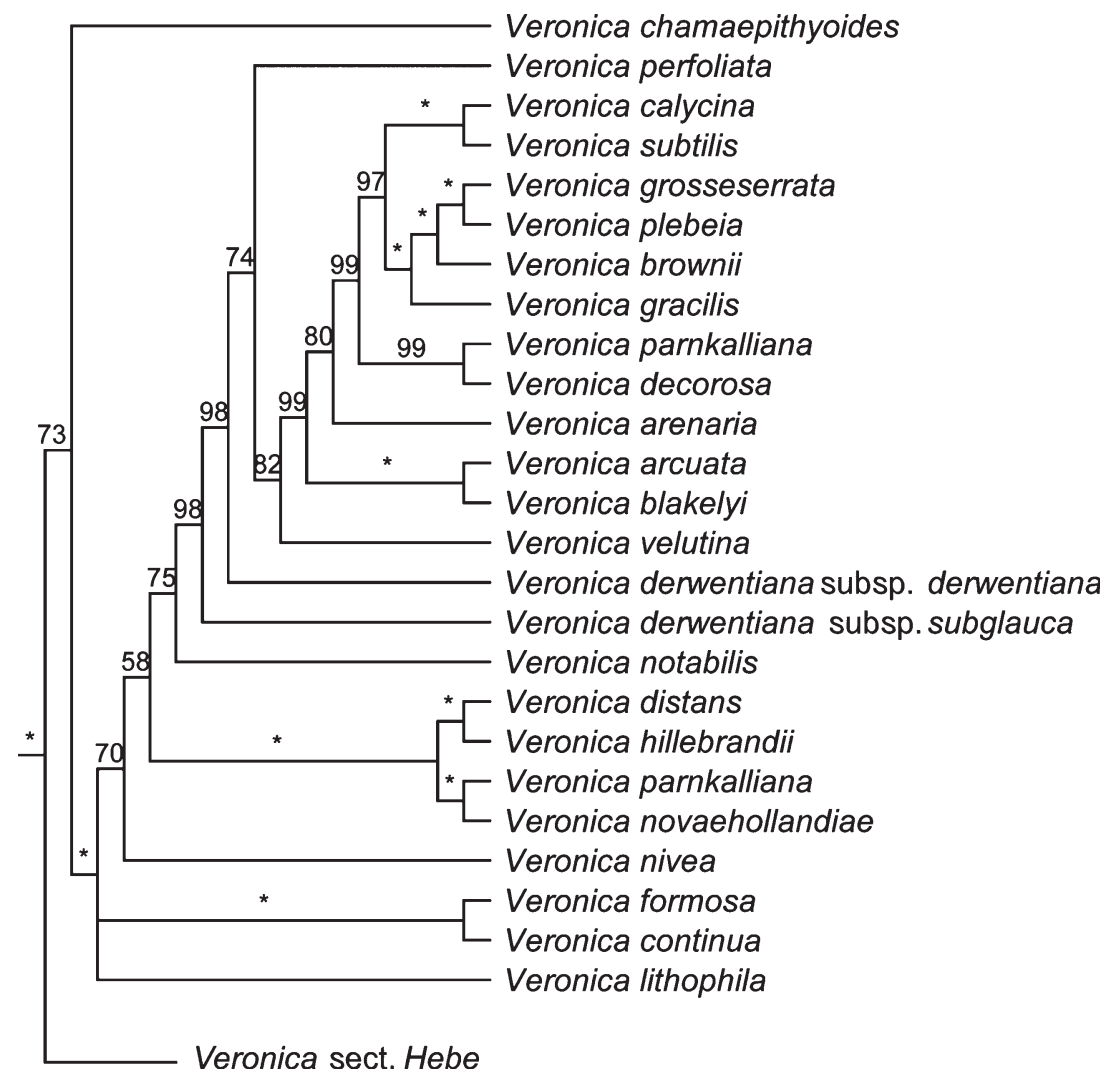

Fig. 4. Consensus of 10000 trees (burnin $=2500000$ generations) from the Bayesian analysis of the dataset from Albach and Meudt (2010), with the new ITS sequences from Veronica section Labiatoides. Only sequences representing $V$. section Labiatoides and $V$. chamaepithyoides are shown. Numbers above branches indicate posterior probabilities. Asterisks indicate $100 \%$ posterior probability.

from Australia (e.g. Wagstaff and Garnock-Jones 1998; Wagstaff et al. 2002; Albach et al. 2005c; Albach and Meudt 2010). The most extensive sampling was the seven species included by Wagstaff et al. (2002), with a topology congruent with ours and representing most of the diversity in our phylogeny (Fig. 3). The non-monophyly of the section in plastid-DNA analyses by Wagstaff et al. (2002), Albach et al. (2005c) and Albach and Meudt (2010) will need further investigation, although these phylogenies do not make sense morphologically and are not congruent with each other in regard to the Australian species. For example, whereas $V$. brownii Roem. \& Schult. (as $V$. arguta) clustered with $V$. nivea and was distant from $V$. formosa in the $r b c \mathrm{~L}$ analysis of Wagstaff et al. (2002), it clustered with $V$. formosa and was distant from $V$. nivea in the $\operatorname{trn} \mathrm{L}-\mathrm{F}$ analysis of Albach et al. (2005c). We, therefore, hypothesise that the irregular behaviour of plastid-DNA sequences is caused by the low sequence divergence and tentatively consider the section monophyletic, although we cannot exclude introgressant hybridisation or ancient lineage sorting.

Although no formal intrasectional classification has been published so far, several authors have delimited groups within the Australian Veronica species either by assigning species to different sections (Römpp 1928; Bentham 1846) or genera (e.g. Briggs and Ehrendorfer 1992; Heads 1994), which are all now completely subsumed under the name Veronica, or by giving informal names (Briggs and Ehrendorfer 2006). The latter authors designated all somewhat woody species to the Derwentia clade, the herbaceous species to the Calycina clade and $V$. continua and $V$. formosa to the Formosa clade. None of these groupings can be upheld on the basis of our results because the herbaceous taxa form two distinct clades (Calycina clade and Distans clade sensu Fig. 3), rendering the Derwentia clade paraphyletic and, at least in the plastid-DNA analyses, $V$. continua does not form a clade with $V$. formosa.

The trees resulting from plastid-DNA and rDNA present substantially different phylogenies. The two datasets are markedly different, with the former including just a third as many parsimony-informative characters as the latter but showing a much higher CI and RI. Thus, although the ITS tree may give more information, this information may be hidden among homoplastic characters. In contrast, the plastid-DNA dataset may be hampered by a small number of informative characters indicative of a low substitution rate. This may lead to topologies reflecting shared ancestral gene pools that did not sort out into monophyletic haplotype groups for each species because of the short time since speciation. These problems are not easy to overcome because sequencing additional plastid markers and even additional accessions is 
unlikely to solve them. Results from the two datasets will be discussed in the light of these difficulties. Both markers suggest multiple shifts between the soft-wooded habit of the former Derwentia species and a fully herbaceous habit and disagree with previous hypotheses on relationships to a considerable extent.

The Tasmanian endemic species $V$. continua and $V$. formosa are supported as sister taxa in the ITS analysis (Fig. 3) but not the $n d h \mathrm{~F}-r p l 32$ analysis. Indeed $V$. continua has strikingly incongruent placements in the two trees, whereas the position of $V$. formosa is more consistent. This raises the possibility that $V$. continua may be of hybrid origin or, through introgression, shares a cpDNA lineage with $V$. derwentiana subsp. derwentiana, which has a widespread distribution, including Tasmania. The Tasmanian endemics show marked similarity in their oblong to lanceolate thick-textured leaves that are stem-clasping, often recurved, with entire margins and glabrous, except for rigid white cilia on the margins near the base. In this combination of characters, they differ from all other Australian species. $V$. continua differs from $V$. formosa mainly in the taller growth, less stem branching and longer racemes, all being features in which it resembles $V$. derwentiana. If these differences do not indicate hybridogeneous influence from $V$. derwentiana in $V$. continua, they could alternatively represent adaptations to the sheltered (although rocky) habitats of $V$. continua, whereas $V$. formosa mostly occurs at more exposed sites.

The differentiation of the Distans clade from the Calycina clade in analyses from both markers is plausible considering the ecology (Distans clade on calcareous sand or limestone, Calycina clade in shady, moist forests or grasslands) and morphology. The members of the Distans clade are widely separated, with $V$. distans occurring in southern Western Australia, $V$. novae-hollandiae in Tasmania and $V$. hillebrandii in South Australia, although all are coastal. They share a habit of erect or sprawling stems linked by stolons or rhizomes, serrate leaves and large flowers, mostly few in the raceme. Unless these are symplesiomorphies, $V$. notabilis should, on the basis of this differentiation, be considered part of the Calycina clade. Our sample of $V$. parnkalliana would be an inter-clade hybrid on the basis of the presence of divergent alleles in the investigated individual (see below).

The next branches in the ITS tree lead to $V$. notabilis and to the Formosa clade of Briggs and Ehrendorfer (2006), together with $V$. lithophila and $V$. nivea. The coherence of the Formosa clade has been questioned above; however, $V$. formosa and $V$. nivea also associate in the plastid tree. $V$. lithophila and $V$. nivea both appear to be distinctive and somewhat isolated species, with different relationships in the two trees. Eight taxa formerly referred to Derwentia form the next branches of the ITS tree, although they are not grouped as a clade and form the greater part of two distinct clades in the plastid tree. The Derwentia assemblage is paraphyletic with respect to the Calycina clade of herbaceous species in the ITS tree, with the subspecies of $V$. derwentiana being widely separated in the plastid tree and less so in the ITS tree. However, the monophyly of $V$. derwentiana cannot be tested rigorously because two subspecies have not been sampled and no clear ITS sequence of $V$. derwentiana subsp. maideniana could be retrieved. The
Calycina clade appears in both trees in the same general relationship to species formerly placed in Derwentia.

\section{Hybridisation in Australian Veronica}

Hybridisation is a common theme in Veronica and polyploid hybridisation was estimated to be responsible for $25 \%$ of speciation events in the genus (Albach et al. 2008). Hybridisation is likely also in the Australian Veronica because 5 of the 20 species, for which chromosome numbers are available (Table 1), have polyploid chromosome numbers. However, even homoploid hybrid speciation has been inferred in the genus (Albach et al. 2009). Furthermore, because all species are native to the mesic zone of Australia (with the exception of $V$. distans in Western Australia), there is some continuity of suitable habitats between southern Queensland and Tasmania, so that hybridisation is not excluded by geographic isolation.

The distributions of $V$. derwentiana subsp. derwentiana and $V$. derwentiana subsp. maideniana differ altitudinally and Briggs and Ehrendorfer (1992) reported that in southern New South Wales and Victoria 'above $\sim 750 \mathrm{~m}$ alt. [subsp. derwentiana] is largely replaced by subsp. maideniana and plants morphologically intermediate between these two subspecies.' They also observed that 'plants with intermediate morphological features are common where the ranges of the subspecies adjoin'. The subspecies differ mainly in the broader leaves, often with a cordate base, and more compact inflorescences of subsp. maideniana. However, we find the subspecies to be widely separated in the phylogenetic analyses and what looked like a transitional zone between two subspecies could also be a hybrid zone, possibly also reflected in the highly heterogeneous ITS sequences of subsp. maideniana. However, our sampling in $V$. derwentiana was not dense enough to exclude geographic structure of cpDNA haplotypes in $V$. derwentiana subsp. derwentiana; analysis of $V$. derwentiana subsp. derwentiana sympatric with subsp. maideniana will be necessary in addition to our allopatric sample. A similar case may be made for $V$. derwentiana subsp. subglauca, which grows geographically close to $V$. velutina and with which it shares a similar cpDNA haplotype (Fig. 2); however, it is morphologically and in the ITS tree closer to $V$. derwentiana subsp. derwentiana (Fig. 3). Again, broader sampling $V$. derwentiana, in a phylogeographic framework, would be necessary to distinguish between possible scenarios.

The most surprising case of hybridisation and, yet, that with the strongest signal is the case of $V$. parnkalliana. The following three kinds of evidence revealed by DNA sequencing and phylogenetic analysis suggest some gene exchange between $V$. decorosa and $V$. novae-hollandiae or of the stem lineages of these species: heterogeneous sequences after direct sequencing, multiple alleles after cloning and consistent placement of sequences from different DNA regions after cloning in topological positions close to the putative parents. Alternative explanations, such as retention of ancestral polymorphism, differential lineage sorting or paralogy, could explain the presence of multiple alleles, although they are unlikely to explain the consistent placement with the same putative parents, given that the DNA regions represent the 
nuclear and the plastid genome. Other samples of $V$. parnkalliana would need to be analysed to differentiate among a hybrid origin, some recent introgression influencing the genotype of our analysed sample and other causes.

The relationship of $V$. parnkalliana with $V$. decorosa is not unexpected on the basis of morphological characteristics and occurrence in similar rocky habitats in South Australia, whereas $V$. novae-hollandiae is not sympatric with either species and is morphologically quite different. $V$. parnkalliana has been collected on the South Australian mainland at rocky sites, along a sandstone ridge in the Flinders Range and near Mount Remarkable, and also previously occurred closer to the coast near Port Lincoln (Fig. 5). Although this species is very rarely collected and is extinct in some of these locations, a collection was made from the Northern Lofty District, along the northern boundary of Telowie Gorge Conservation Park, in 1986 by R. J. Bates, who noted in the collection data that $\sim 500$ plants were counted at the collection site. $V$. decorosa occurs in close vicinity to $V$. parnkalliana on the southern Australian mainland, mostly on cliffs and in gorges of the Flinders ranges, with a single disjunct location further to the south-east. Its main occurrences are now separated from $V$. novae-hollandiae in Tasmania by over $1000 \mathrm{~km}$ and, for the disjunct site, over $500 \mathrm{~km}$, across Bass Strait. However, during Pleistocene glacial periods, when the sea level was $\sim 80 \mathrm{~m}$ lower than it is now, Tasmania was connected to the Australian mainland until $\sim 12000$ years before present (Rawlinson 1974). There were then extensive dunefields on the Bassian Plain. V. novae-hollandiae appears well suited to range expansion under these circumstances because its occurrences are coastal, with specimen records from 'nearcoastal vegetated sand dunes' or 'sands just above high water'.

Veronica decorosa has erect (although soft-wooded and presumably short-lived) stems from a perennial base, upwardly curved hairs on stems and leaves, narrow-linear leaves that are mostly entire, elongated racemes of up to 40 flowers and short, broad, but not emarginate, capsules. $V$. novae-hollandiae is a soft herb with short erect stems connected by rhizomes, stems and leaves pilose with recurved hairs, short broad-toothed leaves, large flowers solitary or in few-flowered racemes and obcordate capsules. The stems of $V$. parnkalliana appear to be softly woody, hairs sparse, very short and upwardly curved, the leaves pinnately lobed, with short linear segments, the racemes elongated, with up to 15 flowers widely spaced, and the capsules flattened and emarginate. The leaf shape, inflorescences and capsules of $V$. parnkalliana may show some degree of intermediate morphology between $V$. decorosa and $V$. novaehollandiae; however, there is little sign of such intermediacy in indumentum.

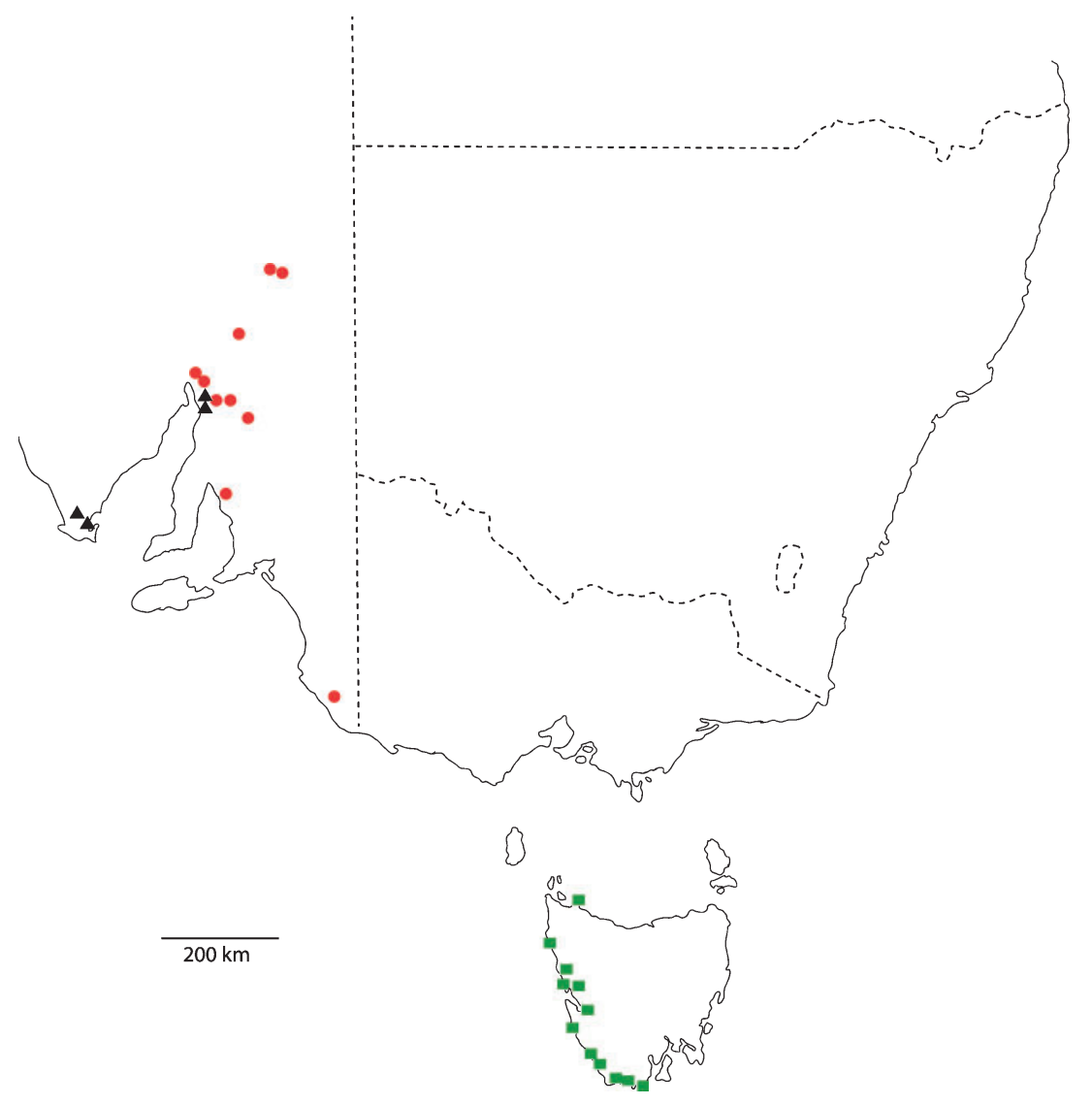

Fig. 5. South-eastern Australia, showing the distribution of Veronica decorosa (circles), $V$. parnkalliana (triangles) and V. novae-hollandiae (squares). (Adapted from Australia's Virtual Herbarium 2012, see www.avh.ala.org.au, accessed 18 June 2012). 
Unfortunately, no chromosome number is available for $V$. parnkalliana (and $V$. novae-hollandiae) to distinguish homoploid from polyploid hybridisation. The most surprising finding of the present study is the presence of two different plastid types in the plant of $V$. parnkalliana that we sampled (heteroplasmy). Maternal inheritance of plastids is considered predominant in angiosperms and was found in $V$. polita $\mathrm{Fr}$. and $V$. linariifolia Pall. ex Link (Zhang et al. 2003). Despite the wide use of plastid-DNA sequences in phylogenetic and phylogeographic analyses in the genus, such heterogeneous sequences indicative of the presence of two plastid types in one individual have not been found before, although the presence of two types occurs at least sometimes in $\sim 20 \%$ of angiosperms (Nagata 2010). Therefore, some closer inspection of the origin of $V$. parnkalliana is warranted and paternal inheritance of plastid DNA in Veronica is still considered a rare event. Nevertheless, given the prevalence of hybridisation in the genus, even a rare event with subsequent return to a homoplasmic condition could confound inference from phylogenetic analyses (Wolfe and Randle 2004).

\section{Character evolution}

Because the species of this group have at times been classified in four different genera, it is worth discussing some of the characters previously used for classifying these species. Hong (1984), in a cladistic analysis of the tribe Veroniceae, used the woody habit, presence of a pulvinus (a swelling on the stem below the base of the petiole) and a crustaceous fruit texture to delimit a clade comprising Detzneria and a 'Hebe group' consisting of Hebe, Parahebe and Chionohebe (now Veronica section Hebe and Labiatoides). However, Hong (1984) did not consider the Australian species explicitly and possibly considered the herbaceous species as part of Veronica and the somewhat woody species as part of the 'Hebe group'. The shrubby habit has been used to classify $V$. formosa in the genus Hebe when all other species in Australia have been classified in other genera; however, on the basis of the present phylogenetic understanding of the Australian and the New Zealand species, this is a parallelism, as is likely the connate leaves stated by Briggs and Ehrendorfer (1992) as a synapomorphy for Hebe including $V$. formosa. Indeed, those authors pointed out that the stems of $V$. formosa, although erect and woody, are short-lived, becoming procumbent after a few flowering seasons. Also, they indicated that there is a gradation of habit types between this and the species with stems that are replaced annually. The difficulties of classifying woodiness in Veronica extend to $V$. subgenus Stenocarpon (Boriss.) M.M.Mart. Ort., Albach \& M.A.Fisch., sister group to the southern hemisphere species on the basis of ITS sequence data (e.g. Albach and Meudt 2010).

The higher chromosome base number $x=20$ or $x=21$ was an essential part of the justification for segregating Parahebe from Veronica (Oliver 1944) and has been used by, for example, Briggs and Ehrendorfer (1992) to delimit the southern hemisphere species from those in the northern hemisphere. Wagstaff and Garnock-Jones (1998) hypothesised an ancestral chromosome number of $x=21$ for the southern hemisphere species of Veronica, with $x=20$ being derived multiple times from that base. Comparison of known chromosome numbers (Table 1) with our phylogenies revealed a more complex picture, with no easy inference for an ancestral chromosome number, although $x=21$ still appears to be the most plausible number on the basis of outgroup comparison, with $x=18$ apparently being derived in the Calycina clade and $V$. notabilis and $V$. hillebrandii- $V$. distans. The base number $x=19$ appears either homoplasious (Fig. 2) or transitional to $x=18$ (Fig. 3).

Briggs and Ehrendorfer (1992) originally considered that $V$. lithophila shared with Parahebe the distinctive corolla-lobe folds shown in a photograph purported to be of newly opened flowers of that species; however, later (Briggs and Ehrendorfer 2006) they reported that the photographed plant had been misidentified and that $V$. lithophila has flat lateral corolla lobes.

The Derwentia clade and the Calycina clade of Briggs and Ehrendorfer (1992) had also been distinguished by Bentham (1846) on the basis of capsule shape. Indeed, capsules in the Calycina clade are broader than long, laterally compressed and shallowly emarginate, whereas those in the Derwentia clade are mostly longer than wide, scarcely compressed and range from acute to emarginate. Although, capsule shape in the Calycina clade resembles that in most species of Veronica, capsule shape in $V$. derwentiana is very similar to that of many species in $V$. subgenus Stenocarpon. Thus, we can assume an evolution towards broader capsules in the Calycina clade and, possibly, a plesiomorphic type of capsule shape in $V$. derwentiana, although a character optimisation across the genus would be necessary to test this pattern.

\section{Acknowledgements}

The authors are grateful to M. Kever for technical support and H. Meudt for sharing unpublished sequences of $V$. salicifolia. We also thank Michael Bayly, Phil Garnock-Jones and Peter Weston for valuable comments on the manuscript.

\section{References}

Albach DC (2008) Further arguments for the rejection of paraphyletic taxa: Veronica subgen. Pseudolysimachium (Plantaginaceae). Taxon 57, 1-6. Albach DC, Chase MW (2001) Paraphyly of Veronica (Veroniceae; Scrophulariaceae): evidence from the internal transcribed spacer (ITS) sequences of nuclear ribosomal DNA. Journal of Plant Research 114, 9-18. doi:10.1007/PL00013971

Albach DC, Meudt HM (2010) Phylogeny of Veronica in the southern and northern hemispheres based on plastid, nuclear ribosomal and nuclear low-copy DNA. Molecular Phylogenetics and Evolution 54, 457-471. doi:10.1016/j.ympev.2009.09.030

Albach DC, Martínez Ortega MM, Chase MW (2004a) Veronica: parallel morphological evolution and phylogeography in the Mediterranean. Plant Systematics and Evolution 246, 177-194. doi:10.1007/s00606-004-0148-9

Albach DC, Martínez Ortega MM, Fischer MA, Chase MW (2004b) Evolution of Veroniceae: a phylogenetic perspective. Annals of the Missouri Botanical Garden 91, 275-302.

Albach DC, Martínez Ortega MM, Fischer MA, Chase MW (2004c) A new classification of the tribe Veroniceae - problems and a possible solution. Taxon 53, 429-452. doi:10.2307/4135620

Albach DC, Meudt HM, Oxelman B (2005a) Piecing together the 'new' Plantaginaceae. American Journal of Botany 92, 297-315. doi:10.3732/ajb.92.2.297 
Albach DC, Jensen SR, Özgökce F, Grayer RJ (2005b) Veronica: chemical characters for the support of phylogenetic relationships based on nuclear ribosomal and plastid DNA sequence data. Biochemical Systematics and Ecology 33, 1087-1106. doi:10.1016/j.bse.2005.06.002

Albach DC, Utteridge T, Wagstaff SJ (2005c) Origin of Veroniceae (Plantaginaceae, formerly Scrophulariaceae) on New Guinea. Systematic Botany 30, 412-423. doi:10.1600/0363644054223666

Albach DC, Martínez-Ortega MM, Delgado L, Weiss-Schneeweiss H, Özgökce F, Fischer MA (2008) Chromosome numbers in Veroniceae: review and several new counts. Annals of the Missouri Botanical Garden 95, 543-566. doi:10.3417/2006094

Albach DC, von Sternburg M, Scalone R, Bardy K (2009) Phylogenetics, morphology and differentiation of Veronica saturejoides (Plantaginaceae). Botanical Journal of the Linnean Society 159, 616-636. doi:10.1111/j.1095-8339.2009.00958.x

Angiosperm-Phylogeny-Group (2003) An update of the Angiosperm Phylogeny Group classification for the orders and families of flowering plants: APG II. Botanical Journal of the Linnean Society 141, 399-436. doi:10.1046/j.1095-8339.2003.t01-1-00158.x

Bentham G (1846) Scrophulariaceae. In 'Prodromus systematis naturalis regni vegetabilis. Vol. 10'. (Ed. A de Candolle) pp. 448-491. (Victor Masson: Paris)

Bentham G (1869) 'Flora Australiensis. Vol. IV.' (L. Reeve \& Co.: London)

Blattner FR (1999) Direct amplification of the entire ITS region from poorly preserved plant material using recombinant PCR. BioTechniques 27, 1180-1186.

Briggs BG, Ehrendorfer F (1968) New combinations in Parahebe (Scrophulariaceae). Taxon 17, 742. doi:10.2307/1218023

Briggs BG, Ehrendorfer F (1992) A revision of the Australian species of Parahebe and Derwentia (Scrophulariaceae). Telopea 5, 241-287.

Briggs BG, Ehrendorfer F (2006) New Australian species and typifications in Veronica sens. lat. (Plantaginaceae). Telopea 11, 276-292.

Brummitt RK (2006) Am I a bony fish? Taxon 55, 268-269. doi: $10.2307 / 25065576$

Garnock-Jones P (1993) Phylogeny of the Hebe complex (Scrophulariaceae: Veroniceae). Australian Systematic Botany 6, 457-479. doi:10.1071/SB9930457

Garnock-Jones PJ, Albach D, Briggs BG (2007) Botanical names in southern hemisphere Veronica (Plantaginaceae): sect. Detzneria, sect. Hebe, and sect. Labiatoides. Taxon 56, 571-582.

Heads M (1994) A biogeographic review of Parahebe (Scrophulariaceae). Botanical Journal of the Linnean Society 115, 65-89.

Hong D-Y (1984) Taxonomy and evolution of the Veroniceae (Scrophulariaceae) with special reference to palynology. Opera Botanica 75, 5-60.

Müller K (2005) SeqState: primer design and sequence statistics for phylogenetic DNA datasets. Applied Bioinformatics 4, 65-69.
Nagata N (2010) Mechanisms for independent cytoplasmic inheritance of mitochondria and plastids in angiosperms. Journal of Plant Research 123, 193-199. doi:10.1007/s10265-009-0293-x

Oliver WRB (1944) The Veronica-like species of New Zealand. Records of the Dominion Museum 1, 228-231.

Posada D (2008) jModelTest: phylogenetic model averaging. Molecular Biology and Evolution 25, 1253-1256. doi:10.1093/molbev/msn083

Rawlinson PA (1974) Biogeography and ecology of the reptiles of Tasmania and the Bass Strait area. In 'Biogeography and ecology in Tasmania'. (Ed. WD Williams) pp. 291-338. (W. Junk: The Hague, The Netherlands)

Römpp H (1928) Die Verwandtschaftsverhältnisse in der Gattung Veronica. Repertorium Specierum Novarum Regni Vegetabilis. Beihefte 50, 1-171.

Ronquist F, Huelsenbeck JP (2003) MrBayes 3: Bayesian phylogenetic inference under mixed models. Bioinformatics 19, 1572-1574. doi:10.1093/bioinformatics/btg180

Shaw J, Lickey EB, Schilling EE, Small RL (2007) Comparison of whole chloroplast genome sequences to choose noncoding regions for phylogenetic studies in angiosperms. the tortoise and the hare III. American Journal of Botany 94, 275-288. doi:10.3732/ajb.94.3.275

Simmons MP, Muller K, Norton AP (2007) The relative performance of indelcoding methods in simulations. Molecular Phylogenetics and Evolution 44, 724-740. doi:10.1016/j.ympev.2007.04.001

Swofford DL (2002) 'PAUP* phylogenetic analysis using parsimony (*and other methods).' (Sinauer Associates: Sunderland, MA)

Wagstaff SJ, Garnock-Jones PJ (1998) Evolution and biogeography of the Hebe complex (Scrophulariaceae) inferred from ITS sequences. New Zealand Journal of Botany 36, 425-437. doi:10.1080/0028825X.1998.9512581

Wagstaff SJ, Bayly MJ, Garnock-Jones PJ, Albach DC (2002) Classification, origin, and diversification of the New Zealand Hebes (Scrophulariaceae). Annals of the Missouri Botanical Garden 89, 38-63. doi: $10.2307 / 3298656$

Wettstein Rv (1891) Scrophulariaceae. In 'Die natürlichen Pflanzenfamilien'. (Eds A Engler, K Prantl) pp. 39-107. (Wilhelm Engelmann: Leipzig, Germany)

White TJ, Bruns T, Lee S, Taylor J (1990) Amplification and direct sequencing of fungal ribosomal RNA genes for phylogenetics. In 'PCR protocols: a guide to methods and applications'. (Eds M Innis, D Gelfand, J Sninsky, T White) pp. 315-322. (Academic Press: San Diego, CA)

Wolfe AD, Randle CP (2004) Recombination, heteroplasmy, haplotype polymorphism, and paralogy in plastid genes: implications for plant molecular systematics. Systematic Botany 29, 1011-1020. doi:10.1600/0363644042451008

Zhang Q, Liu Y, Sodmergen (2003) Examination of the cytoplasmic DNA in male reproductive cells to determine the potential for cytoplasmic inheritance in 295 angiosperm species. Plant \& Cell Physiology 44, 941-951. doi:10.1093/pcp/pcg121 